\title{
Experimental study of the effect of blade pitch angle on the wind turbine performance at low wind speed condition
}

\author{
Riyanto $^{\mathrm{a}}$, Nugroho Agung Pambudi ${ }^{\mathrm{a}^{*}}$, Bayu Rudiyanto ${ }^{\mathrm{b}}$, Nyenyep Sri Wardani ${ }^{\mathrm{a}}$, \\ Rusdi Febriyanto ${ }^{\text {a }}$ Kukuh Mukti Wibowo ${ }^{\text {a }}$, Nova Dany Setyawan ${ }^{\mathrm{a}}$, Basori ${ }^{\mathrm{a}}$, \\ Saeid Mohammad zadeh Bina ${ }^{\mathrm{c}}$ \\ ${ }^{a}$ Mechanical Engineering Education Department, Universitas Sebelas Maret, Jl. Ir. Sutami No.36A, Surakarta, Jawa Tengah 57126, \\ Indonesia \\ ${ }^{b}$ Energy Engineering Laboratory, Department of Renewable Engineering, Politeknik Negeri Jember, Jember 68121, \\ Indonesia \\ ${ }^{c}$ Graduate School of Engineering and Resource Science, Akita University, Akita, Japan
}

\begin{abstract}
While wind energy is widely used across the world, its utilization, especially in cases where the speed of wind is low, has not been optimized. This study aimed at establishing the impact of pitch angle magnitude utilized in horizontal wind turbines at low speed. A NACA 6412 type airfoil made from mahogany's wood was installed to a wind tunnel to measure the performance. The effect of pitch angle was determined at low wind speeds using $0^{\circ}, 2^{\circ}, 4^{\circ}, 6^{\circ}, 8^{\circ}, 10^{\circ}$, and $12^{\circ}$ angles. The speed was varied between $1 \mathrm{~m} / \mathrm{s}$ and $5 \mathrm{~m} / \mathrm{s}$. The wind originated from a blower installed and was controlled by an anemometer to determine the speed. The findings of the study established that the variation of pitch angles results to differences in power and rotation of the rotor produced by the wind turbines. The output of the experiment was current and voltage converted to power and total efficiency. The highest electrical power of $9.7240 \mathrm{~W}$ was produced at the most optimal pitch angle of $8^{\circ}$ and a wind speed of $5 \mathrm{~m} / \mathrm{s}$. In the end, the study showed that horizontal wind turbines with NACA 6412 and $8^{\circ}$ pitch angle produce the highest total efficiency at $11.2 \%$ and $5 \mathrm{~m} /$ s speed.
\end{abstract}

Keywords: Wind turbine, Pitch angle, low wind speed, electric power

\section{Introduction}

Over the years, there has been a constant increase in the rate of population growth. In the year 2017, the world's population had reached 7.6 billion. It is projected that the world's population will reach an estimated 11.2 billion people in the year 2100 [1]. This constant increase in population growth has led to the increase in the use of fossil fuel.

Indonesia, being a developing country, has problems with the use of fossil energy. Fossil energy does not last long due to the country's high population density. By 2020, the population of Indonesia is estimated to reach 271 million people [2]. Fossil fuels (such as petroleum, natural gas, and coal) are a major source of energy in Indonesia. These fuels are estimated to run out within the next 13, 34 and 72 years, respectively [3]. Thus, there is need to consider the use of alternative sources of renewable energy in order to overcome the country's dependence on fossil fuels. Notable examples of alternative sources of energy includes water, sun, wind, biogas, geothermal, biomass and sea waves.

Wind energy is a renewable energy that is widely used in today's world. Nevertheless, the utilization of wind energy in Indonesia has not been optimized. From 970 MW, the new available potential is utilized at $1.96 \mathrm{MW}$, which is only about $0.003 \%$ [4]. The low utilization of wind energy in Indonesia is due to the low average wind speed of 2 to $5 \mathrm{~m} / \mathrm{s}$ in the country [1]. Thus results in the poor generation of

\footnotetext{
* Manuscript received August 7, 2018; revised July 15, 2019.

Corresponding author. Tel.: (0271) 718419; E-mail address: agung.pambudi@ staff.uns.ac.id

doi: $10.12720 /$ sgce.8.5.627-632
} 
optimum electric power by the wind turbine.

The performance of horizontal wind turbines at low wind speeds can be optimized by airfoil type planning and pitch angle setting [5]-[8]. The pitch angle setting is used to adjust the initial torque of the rotor and the generator thereby enabling the turbine to rotate at low wind speeds. The pitch angle is the angle between the chord line and the wind turbine spin field [9]. The studies conducted by Atmadi and Ahmad [7], Musyafa and Ronny [8], Faqihuddin et al. [10], and Rocha et al. [11] documented that pitch angle variations affect the cut-in speed, power, and coefficient of power produced by wind turbines. Each wind turbine design has an optimum pitch angle, the addition of a pitch angle that is above the optimum angle leads to a decrease in the performance of the horizontal wind turbine. Therefore, it is quintessential to set the optimum pitch angle that is required to adjust the wind turbine design with wind speed in order to improve the performance of the horizontal wind turbine. In relation to existing studies on the research and development of wind turbines, this study aimed to investigate the effect of pitch angle modification at low wind speed on the production of optimum power in a horizontal wind turbine. The findings generated in this research were used to analyze the performance of the horizontal wind turbine in each test variation, in order to determine which wind turbine design produces optimal electric power.

\section{Research Method}

\subsection{Experimental set-up}

This research was conducted to determine the effect of a diffuser on the performance of a horizontal wind turbine. The wind turbine comprised of an untwisted blade of $160 \mathrm{~mm}$ blade length and a NACA 6412 airfoil which has a high lift and drag ratio at a low Reynolds Number [12]. The full specifications of the components of the wind turbine used in this study are shown in Table 1.

Table 1. Specifications of the wind turbine

\begin{tabular}{ll}
\hline Components of wind turbine & \multicolumn{1}{c}{ Specification } \\
\hline Generator & 100 Watt \\
Rotating Rotor with a Generator & $1: 1$ \\
Diameter of the rotor & $1200 \mathrm{~mm}$ \\
Length of blade & $600 \mathrm{~mm}$ \\
Total number of blades & 3 \\
Blade material & Mahogany Wood \\
\hline
\end{tabular}

Generally, the pitch angle is set in various operational conditions in order to adjust the wind speed. The pitch angle variations used in this research includes $0^{\circ}, 2^{\circ}, 4^{\circ}, 6^{\circ}, 8^{\circ}, 10^{\circ}, 12^{\circ}$, and $14^{\circ}$ (Figure 1). The actual electric power generated by a wind turbine generator was determined by testing each pitch angle variation with a wind tunnel at low wind speeds which ranged from $1 \mathrm{~m} / \mathrm{s}$ to $5 \mathrm{~m} / \mathrm{s}$. Also, measurements of the rotation of the wind turbine rotor were recorded and used to analyze the total efficiency of the wind turbine.
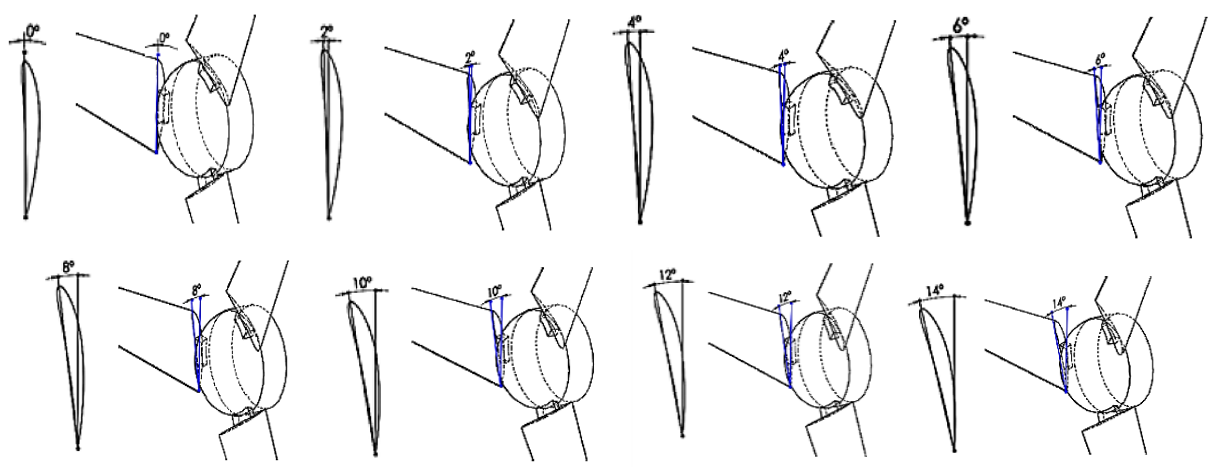

Fig. 1. Pitch angle variations 


\subsection{Experimental design}

The wind tunnel was designed with two openings on the inlet and outlet (open-type wind tunnel) to minimize the blockage effect. The wind turbine was placed on a wind tunnel that is $3100 \mathrm{~mm}$ long, 2100 $\mathrm{mm}$ wide and $2500 \mathrm{~mm}$ height (Fig. 2). The electric power of the wind turbine was determined by using a digital multimeter to measure the electric current (in Ampere) and voltage (Volts). Furthermore, a tachometer was used to measure the wind turbine's rotor rotation. The electric power and rotation of the rotor were used to evaluate the power efficiency of the wind turbine.

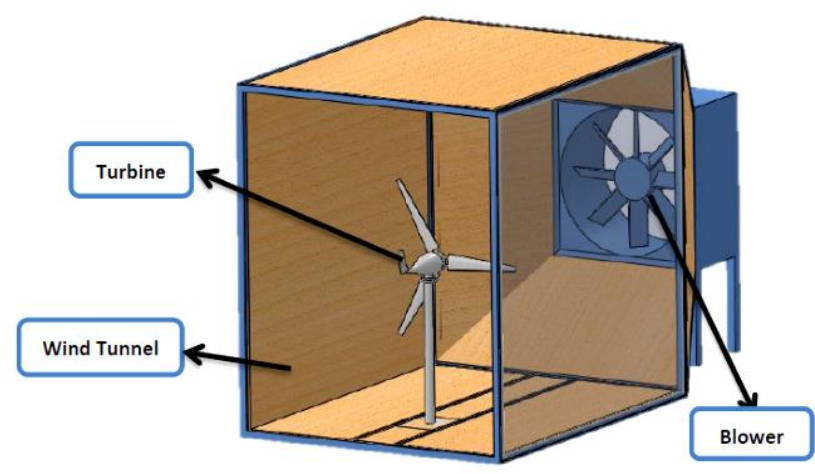

(a)

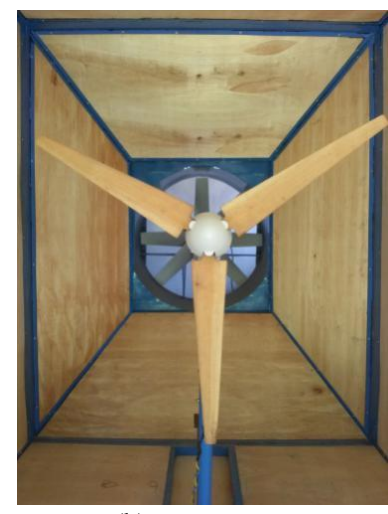

(b)

Fig. 2. (a) Wind tunnel design (b) Wind turbine front view

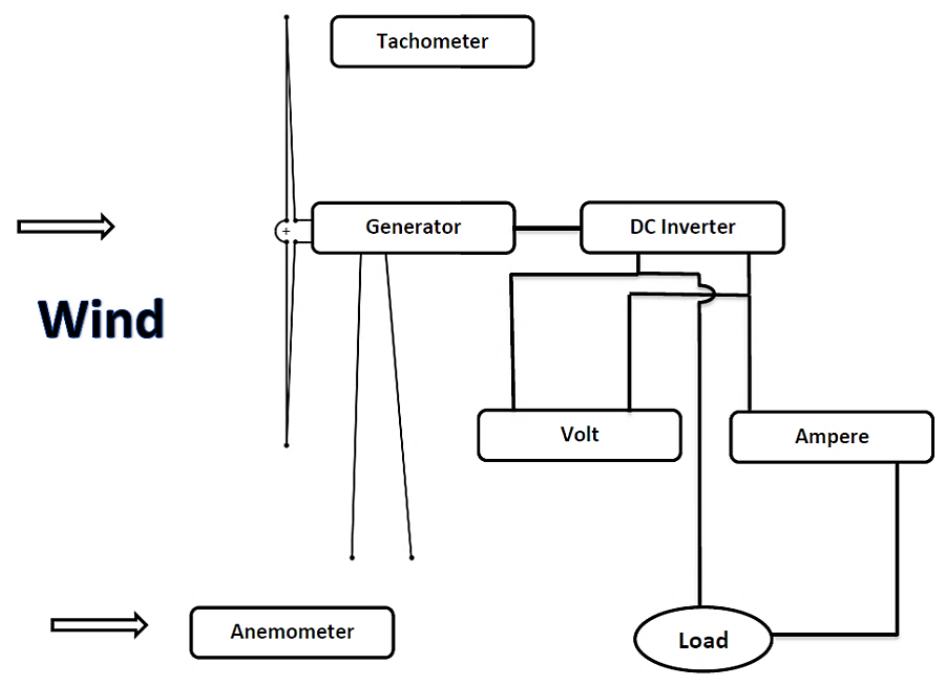

Fig. 3. Data input scheme

\section{Result and Discussion}

\subsection{The effect of pitch angle on the generation of electric power and rotor rotation of the wind turbine}

The electric power and rotation of the rotor produced by the wind turbine varied with the pitch angle of the wind turbine blade. Different pitch angles produced different aerodynamic properties in the wind turbine blade which affected the resulting torque, rotation of the rotor and the electrical power generated. The electric power generated and the rotor rotation of NACA 6412 horizontal wind turbine at each variation of pitch angle and wind speed are shown in Fig. 4 (a) and (b). 


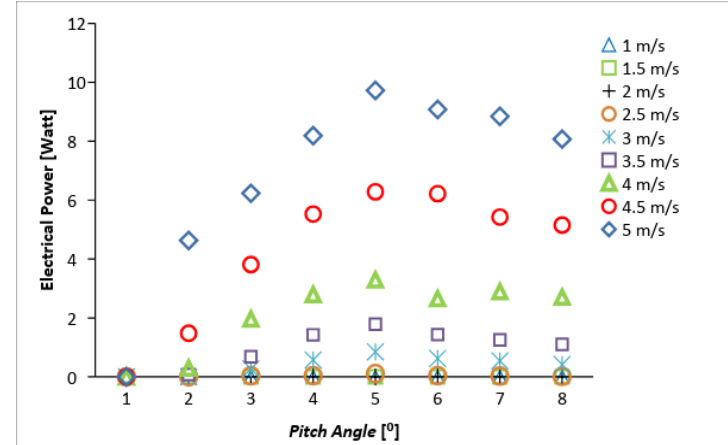

(a)

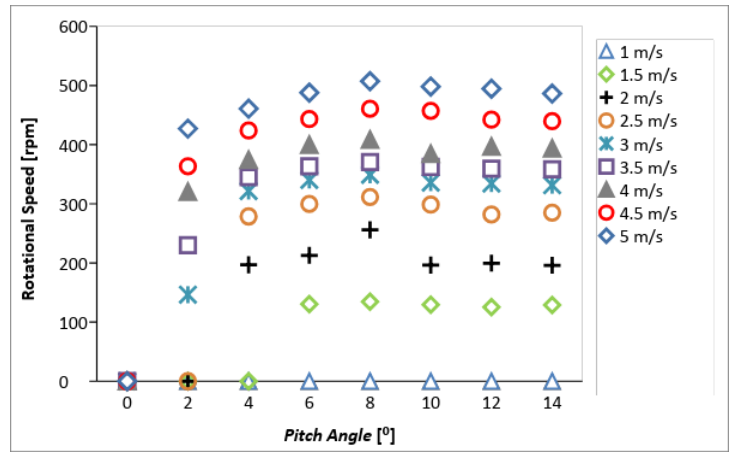

(b)

Figure 4. (a) The effect of different pitch angles on the electric power (b) The effect of different pitch angles on the rotor rotation

The wind turbine did not rotate or produce energy at a pitch angle of $0^{0}$ (Figure 4(a) and (b)). This position of the pitch angle resulted in the generation of torque that was unable to rotate the generator and the wind blades produced a large drag force.

The wind turbine rotated at pitch angles which ranged from $2^{0}$ to $14^{0}$ with different rotor rotation speeds and electric power. At the pitch angle position of $2^{\circ}$, the lowest rotor rotation produced had a wind speed of $2.5 \mathrm{~m} / \mathrm{s}$, while at a pitch angle of $4^{0}$, the lowest rotor rotation produced a wind speed of $2 \mathrm{~m} / \mathrm{s}$. On the other hand, the lowest rotor rotation was produced at a wind speed of $1.5 \mathrm{~m} / \mathrm{s}$ at pitch angles of $6^{0}$ to $14^{0}$ (Figure $4(\mathrm{~b})$ ). Even though the wind turbine was spinning at these wind speeds, it did not produce electric power. This is because the rotation of the rotor was not strong enough to generate electromagnetic induction on the generator used, thereby affecting the cut-in speed. At a pitch angle of $2^{0}$, cut-in speed was $3.5 \mathrm{~m} / \mathrm{s}$ of wind speed while at the pitch angles from $4^{0}$ to $14^{0}$ cut-in speed is $2.5 \mathrm{~m} / \mathrm{s}$.

An increase in pitch angles from $2^{0}$ to $8^{0}$ resulted in an increase in electric power generated (from $4.6334 \mathrm{~W}$ to $9.7240 \mathrm{~W}$ ) and rotor rotation, while a further increase in pitch angle above $8^{\circ}$, (from $10^{0}$ to $14^{0}$ ) resulted in a decrease in electric power generated and rotor rotation of the wind turbine. The maximum power at all wind speed variations is achieved at $8^{0}$ pitch angle because the maximum rotation of rotors is achieved at this angle. At a wind speed of $5 \mathrm{~m} / \mathrm{s}$, the maximum power produced was 9.7240 Watt and at a rotor speed of $507.10 \mathrm{rpm}$. The maximum powers produced at a wind speed of $5 \mathrm{~m} / \mathrm{s}$ for different pitch angles includes the following: $9.0794 \mathrm{~W}$ at $10^{\circ}, 8.8434 \mathrm{~W}$ at $12^{\circ}, 8.1871 \mathrm{~W}$ at $6^{\circ}, 8.0716$ $\mathrm{W}$ at $14^{0}, 6.2321 \mathrm{~W}$ at $4^{0}$, and $4.6334 \mathrm{~W}$ at $2^{\circ}$. At a pitch angle of $0^{\circ}$, no electrical power was produced. This decrease in power is due to the decrease in angle of attack and the resulting lift force. This decrease in lift force resulted in a decrease in torque, rotor rotation and power generated by the wind turbine [5].

Based on the findings generated in this study, it can be inferred that the optimum pitch angle is $8^{\circ}$ The large rotation speed of the rotor generated at the pitch angle variation of $8^{0}$ produced the greatest torque compared to other pitch angles. This indicates that the installation of the turbine blade at $8^{0}$ pitch angle is more effective in increasing the electrical power generated by the wind turbine. Therefore, the ideal pitch angle for the design of this NACA 6412 wind turbine is $8^{\circ}$ pitch angle.

\subsection{NACA 6412 wind turbine performance}

The wind turbine performance was determined by measuring its tip speed ratio $(\lambda)$ and power efficiency (n). Tip speed ratio is the ratio of the rotational speed of the rotor to the wind speed of the rotor while the Power Efficiency is the ratio of the actual power generated by the turbine divided by the power contained in the wind. The power efficiency measured in this study is the total power efficiency of the wind turbine power after passing through a generator and an inverter. The results showed that the optimum power of NACA 6412 wind turbine was generated at $8^{\circ}$ pitch angle variation. The different calculated values of Tip Speed Ratio and Power Efficiency at different wind speeds are shown in Figures 5 (a) and (b). 


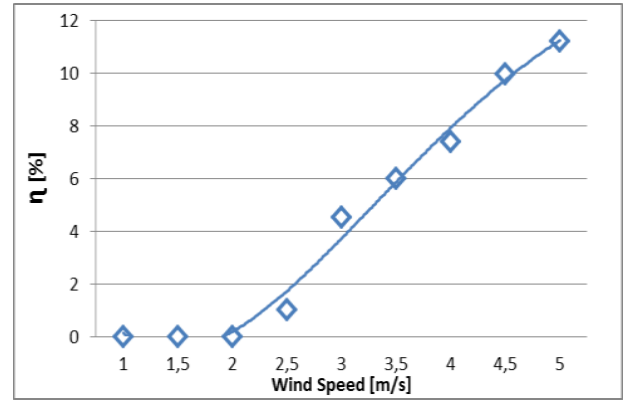

(a)

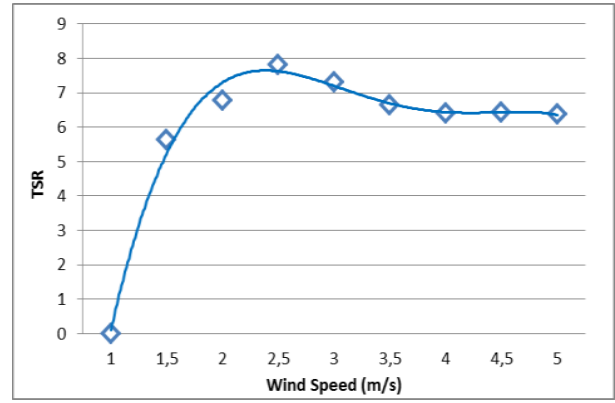

(b)

Figure 5. (a) The effect of wind speed on the power efficiency (b) The effect of wind speed on the tip speed ratio

The highest power efficiency produced of $11.2 \%$ was produced at a wind speed of $5 \mathrm{~m} / \mathrm{s}$ (Fig. 5(a)). Fig. 5(b) shows the relationship between wind speed and the tip speed ratio. The horizontal wind turbine has the highest TSR of 7.82 at a wind speed of $2.5 \mathrm{~m} / \mathrm{s}$. An increase in wind speed from $1 \mathrm{~m} / \mathrm{s}$ to $2.5 \mathrm{~m} / \mathrm{s}$ resulted in an increase in TSR value significantly. However, a further increase in wind speed from $3 \mathrm{~m} / \mathrm{s}$ to $5 \mathrm{~m} / \mathrm{s}$ resulted in a decrease in TSR.

The relationship between TSR and the power efficiency of the wind turbine at Pitch Angle $8^{0}$ is shown in Fig. 6.

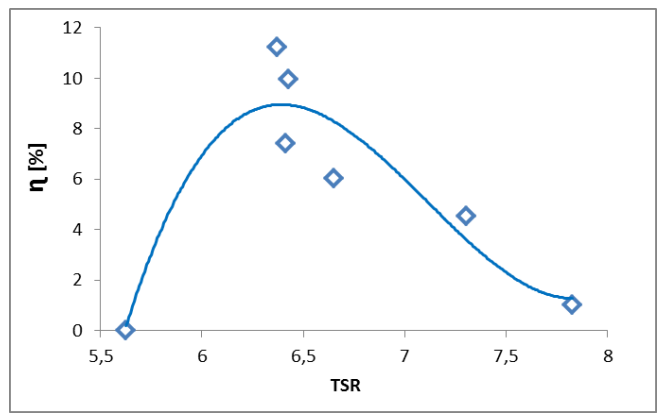

Figure 6. The relationship between TSR and power efficiency of the wind turbine at Pitch Angle $8^{0}$

Under the initial conditions, the power efficiency continued to increase as the TSR increased.. At the maximum value, the resulting power efficiency began to decrease. The efficiency decreased because the speed of rotation of the wind turbine blocked the wind from passing through the rotor. Thus, it can be inferred that the tip speed ratio has a direct impact on the power generated [13]. The finding in this study shows that the power efficiency and tip speed ratio were influenced by the design of the rotor, rotor dimensions, wind speed, generator, and inverter. The highest power efficiency generated by horizontal wind turbines with NACA 6412 airfoil is $11.2 \%$ at an optimum speed ratio of 6.37 .

\section{Conclusion}

This research study showed that the change in the pitch angle on the horizontal wind turbine blades affect the electrical power and the rotation of the rotor. Pitch angles that are too high or too low reduce the electrical power, and the resulting rotation of the rotor decreases. Each variation of a given pitch angle produces different aerodynamic properties that have an impact on the resulting torque. Each wind turbine design has an optimum pitch angle in which maximum power can be generated. The findings generated in this study showed that that NACA 6412 horizontal wind turbine has an optimal pitch angle of $8^{0}$ in which the highest electrical power is generated. At this angle, a cut-in speed at a low wind speed of $2.5 \mathrm{~m} / \mathrm{s}$ is produced. Furthermore, this study showed that the horizontal wind turbine produced the highest total power efficiency of $11.2 \%$ at a wind speed of $5 \mathrm{~m} / \mathrm{s}$ with an optimized speed ratio tip value of 6.37 . Thus, 
the installation of the turbine blade at a pitch angle of $8^{0}$ is the most effective wind turbine design to generate maximum power in areas with low wind speed conditions.

\section{References}

[1] United Nations, Department of Economic and Social Affairs, Population Division. World Population Prospects: The 2017 Revision, Key Findings and Advance Tables. New York: United Nation; 2017.

[2] Indonesia Central Bureau of Statistics. Indonesian Population Projection 2010-2035. Jakarta: Badan Pusat Statistik; 2013. (In Indonesia)

[3] Ministry of Energy and Mineral Resources. Strategic Plan of the Ministry of Energy and Mineral Resources 20152019.Jakarta: Kementerian Energi dan Sumber Daya Mineral; 2015. (In Indonesia)

[4] Sugiyono A. et al. Outlook Energi Indonesia 2017. Clean Energy Technology Development Initiative.. Jakarta: Pusat Teknologi Sumber Daya Energi dan Industri Kimia (PTSEIK-BPPT) ISBN 978-602-74702-2-4; 2017. (in Indonesia)

[5] Zhang, J. Pitch Angle Control for Variable Speed Wind Turbines. Nanjing, China; 2008.

[6] Manwell JF, McGowan JG, Dan AL. Rogers. Wind Energy Explained - Theory Design and Application Second Edition. London: John Wiley \& Sons Ltd; 2009.

[7] Atmadi, Sulistyo D Ahmad Jamaludin F. Analysis of the effect of pitch angles to obtain the optimal power of the LPN-SKEA wind turbine $50 \mathrm{~kW}$ in some wind speed conditions. Jurnal Teknologi Dirgantara, 2009; 7(1):60-66. (In Indonesia)

[8] Musyafa, Ali dan Ronny Dwi N. Implementation of pitch angle wind turbine posision for maximum power production. Academic Research International, 2012; 3(1).

[9] Johnson, Gary L. Wind Energy System. Sandia: Laboratories Report SAND 78-0962; 2001.

[10] Faqihudin MF, Nizam M, Dan Dominicus DDPT. Characteristics of the untwisted blade wind turbine model using NREL S833 airfoil type at low wind speed. MEKANIKA, 2014; 12(2). (In Indonesia)

[11] Rocha PA. Costa, et al. The effects of blade pitch angle on the performance of small-scale wind turbine in urban environment. Energy, 2018; 148:169-178.

[12] Sutikno, Priyono DDBS. Design and blade optimization of contra rotation double rotor wind turbine. International Journal of Mechanical \& Mechatronics Engineering IJMME-IJENS, 2011; 11 (01).

[13] Kishore, Ravi A, Thibaud C, Dan SP. Small-scale wind energy portable turbine (SWEPT). J. Wind Eng. Ind. Aerodyn, 2013; 116:21-23. 